Research Article

\title{
National Programme on Climate Change and Human Health-India, 2019
}

\author{
Akshay Kumar', Nitin P Mahajan ${ }^{2}$, Rameshwar Sorokhaibam³ ${ }^{3}$ Avinash Sunthlia', \\ Binoy Surendra Babu ${ }^{5}$, Shikha Vardhan ${ }^{6}$, Aakash Shrivastava ${ }^{7}$ \\ 1,2,3,4,5,6,7 National Centre for Disease Control, Ministry of Health and Family Welfare, New Delhi, India. \\ DOI: https://doi.org/10.24321/0019.5138.202029
}

\section{I $\quad \mathbf{N} \quad \mathbf{F} \quad \mathbf{O}$}

\author{
Corresponding Author: \\ Aakash Shrivastava, National Centre for Disease \\ Control, Ministry of Health and Family Welfare, \\ New Delhi, India. \\ E-mail Id: \\ a.shrivastava.ncdc@gmail.com \\ Orcid Id: \\ https://orcid.org/0000-0001-5293-4268 \\ How to cite this article: \\ Kumar A, Mahajan NP, Sorokhaibam R, Sunthlia A, \\ Babu BS, Vardhan S et al. National Programme on \\ Climate Change and Human Health-India, 2019. \\ J Commun Dis 2020; 52(3): 43-48.
}

Date of Submission: 2020-04-01

Date of Acceptance: 2020-08-03

\section{$\begin{array}{llllllll}\mathbf{A} & \mathbf{B} & \mathbf{S} & \mathbf{T} & \mathbf{R} & \mathbf{A} & \mathbf{C} & \mathbf{T}\end{array}$}

Introduction: In 2015, India's response to climate change was broadened by introducing four new missions including "Health". National Action Plan for Climate Change and Human Health (NAPCCHH) was prepared in 2018 with objective to strengthen health care services against adverse impact of climate change on health. The Ministry of Health and Family Welfare (MoHFW) approved National Programme on Climate Change and Human Health (NPCCHH) under National Health Mission (NHM) in February 2019. The common Climate Sensitive Diseases (CSDs) are - air pollution related, heat related, water-borne, vector-borne, cardiopulmonary diseases, mental health, food-borne, nutrition related illnesses etc. Currently the three key areas of focus for NPCCHH include air pollution, heat related illnesses and creation of green and climate resilient healthcare facilities.

Air Pollution and Human Health: Acute Respiratory Illnesses (ARI) surveillance in context of air pollution was started in year 2017 in Delhi. Key Strategy in coming years are to expand ARI surveillance in all polluted cities of States, developing State/District/Cities level health sector adaptation plan for air pollution and health.

Heat and Human Health: Since 2015, heat related illnesses (HRI) surveillance was started from heat vulnerable States of India. Key Strategies in coming year are strengthening the surveillance, standardizing the investigation of deaths due to suspected heat stroke cases, developing State/ District/ City specific heat and health action plan, increasing public awareness and community outreach, developing measures for early warning system/ alerts and response at State, district and below district level.

National Centre for Disease Control (NCDC) under MoHFW is incorporating both the green and climate resilient healthcare principles in revising Indian Public Health Service Guidelines.

Keywords: Climate Change and Health, ARI, Indian Public Health Service (IPHS) guidelines, Surveillance, Climate Resilient Healthcare Facilities 


\section{Introduction}

The United Nations Framework Convention on Climate Change (UNFCC), 1992 defines climate change as 'a change of climate which is attributed directly or indirectly to human activity that alters the composition of the global atmosphere and which is in addition to natural climate variability observed over comparable time periods'. ${ }^{1}$ In the last 130 years, the world has warmed by approximately $0.85^{\circ} \mathrm{C} .^{2} \mathrm{Global}$ warming is likely to reach $1.5^{\circ} \mathrm{C}$ between 2030 and 2052 and the climate-related risks to health are projected to increase with it as well. ${ }^{3}$ Climate change affects health by three basic pathways i.e., directly by change in the frequency of extreme weather including heat, drought and heavy rain, effects mediated through natural system, for e.g., vector borne diseases, water-borne disease and air pollution, effects heavily mediated by human systems, for e.g., occupational impacts, undernutrition, and mental stress. ${ }^{4}$

To mitigate and adapt to climate change, the Prime Minister Council on Climate Change (PMCC), India released National Action Plan on Climate Change (NAPCC) with eight missions in June 2008. ${ }^{5}$ In 2015, India's response to climate change was broadened by introducing four new missions including "Health". The proposed 'Mission on Health' will address the health-related aspects of climate change through multipronged approach. Ministry of Health \& Family Welfare (MoHFW) is the nodal agency and National Centre for Disease Control (NCDC), New Delhi is the nodal technical agency to undertake coordination activities and prepare strategies. Accordingly, National Action Plan for Climate Change and Human Health (NAPCCHH) was prepared in $2018 .^{6}$

\section{Vision, Goal and Objectives of NAPCCHH}

Vision: Strengthening of healthcare services for all the citizens of India especially vulnerable like children, women and marginalized population against climate sensitive illnesses.

Goal: To reduce morbidity, mortality, injuries and health vulnerability due to climate variability and extreme weathers

Objective: To strengthen health care services against adverse impact of climate change on health.

The specific objectives are (i) to create awareness among general population (vulnerable community), health care providers and Policy makers regarding impacts of climate change on human health, (ii) to strengthen capacity of healthcare system to reduce illnesses/ diseases due to variability in climate, (iii) to strengthen health preparedness and response by performing situational analysis at National/ state/ district/ below district levels, (iv) to develop partnerships and create synchrony/ synergy with other missions and ensure that health is adequately represented in the climate change agenda in the country, (v) to strengthen research capacity to fill the evidence gap on climate change impact on human health. ${ }^{6}$

To achieve the objectives of the Health Mission, the MoHFW approved National Programme on Climate Change and Human Health (NPCCHH) under National Health Mission in February 2019. Since India is a diverse country with variety of geoclimatic conditions, each State is desired to develop its own State Action Plan for Climate Change and Human health (SAPCCHH).

The SAPCCHH is a detailed document about the health adaptation plans for the common Climate Sensitive Diseases (CSDs), that include - air pollution related, heat related, water-borne, vector borne, cardiopulmonary, mental health, food-borne, nutrition related illnesses etc. It contains region specific statistics about prevalent CSDs, distribution of vulnerable population, roles and responsibilities of the health team and various stakeholders, the health infrastructure and other resources available to help mitigate the effect of climate and extreme weather events.

Apart from this, disease specific Centre of Excellences (CoE) have been identified to help the State programme officers prepare their disease specific adaptation plans. For example, the NPCCHH is coordinating with NVBDCP to sensitize the States on changing pattern of vector borne disease. The National Institute of Malaria Research (NIMR) is involved in formulating adaptation plan for vector borne disease and prepare a model to help predict potential impact of climate variation on vector borne diseases.

Currently the three key areas of focus for NPCCHH include air pollution, heat related illnesses and creation of green and climate resilient healthcare facilities.

\section{Air Pollution and Human Health}

Air pollution is a major and growing risk factor for ill health in India, contributing significantly to the country's burden of disease.

\section{Air Pollution}

It is due to invisible particles of pollution (PM2.5) that penetrate deep into our lungs, bloodstream and bodies. Key health harmful pollutants include particulate matter (PM2.5 and PM10), Carbon Monoxide (CO), Ozone $\left(\mathrm{O}_{3}\right)$, sulphur dioxide and Nitrogen Oxides (NOx), Lead and $\mathrm{NH}_{3}$. According to the global air pollution observatory maintained by World Health Organization, some of the Indian cities are counted as highly polluted cities of the world. ${ }^{7}$

These pollutants are responsible for about one-third of deaths from stroke, chronic respiratory disease, and lung cancer as well as one-quarter of deaths from heart attack. 


\section{Air Quality Monitoring}

In India, Ambient air pollution (AAP) information is collected primarily by the National Air Quality Monitoring Program (NAMP), administered by the Central Pollution Control Board (CPCB), which is part of the Ministry of Environment, Forests and Climate Change (MoEFCC), Gol. MoEFCC has launched a pan India National Clean Air Program (NCAP), it is a time-bound, National strategy to bring down levels of air pollution (PM2.5 and PM10) by $20-30 \%$ by 2024 (compared to 2017 levels). ${ }^{8}$

\section{Effect of Air Pollution on Human Health}

World Health Organization (WHO) estimates that around 7.2 million people die every year from exposure to polluted air, including 4.2 million deaths due to AAP and 3.8 million deaths due to household air pollution. ${ }^{9}$

The report on Global Burden of Disease (GBD) estimates that 1.24 million deaths annually in India were due to air pollution, including 0.67 million from AAP exposure and 0.48 million from household air pollution exposure. ${ }^{10}$

\section{Acute Respiratory Illness (ARI) Surveillance}

MoHFW had acknowledged the problem of air pollution and in year 2017 ARI surveillance in context of air pollution was started in six Central Government tertiary care hospital of Delhi. The ARI data is being correlated with air quality level i.e., Air Quality Index (AQI) of particular area or city. The overarching goal of ARI surveillance is to minimize the impact of the air pollution by providing useful information to public health authorities so they may better plan appropriate control and intervention measures, allocate health resources, and make case management recommendations.

\section{Key Strategy in Coming year for Air Pollution and Human Health Activities}

- Expanding ARI Surveillance in All Polluted Cities of the States: The NPCCHH envisages establishing a surveillance system for monitoring impacts of air pollution on health in each State of the country. In its first phase all the cities that are enlisted under NCAP will be selected followed by selection of 2-4 tertiary hospitals for the ARI surveillance.

- Capacity Building of Medical and Paramedical Staff about Health Impacts of Air Pollution: for further communicating the message into actions to the vulnerable groups.

- Increase Awareness among Different Sections of Populations and Vulnerable Populations: NCDC has prepared IEC for print media and social media and shared it with the all the States to better prepare them and adopt protective measures. Social Media
IEC campaign is running on MoHFW and NCDC social media sites.

- Developing State/District/City Level Health Sector Adaptation Plan for Air Pollution and Health: to ensure better preparedness before and coordination whenever air pollution rises and evaluation at regular interval. The action plan will help in prioritising the most affected areas, the vulnerable groups followed by resource allocation. Action plan will identify the stakeholders, further it will define their roles and responsibilities through operational flowchart or tables.

- Address Research Gap on what interventions are useful to protect health from air pollution. Research on relevant research questions will be undertaken by Indian Council of Medical Research (ICMR).

\section{Heat and Human Health \\ Heat Wave Definition}

Climate change is associated with widespread changes in weather patterns including heat waves. Year 2015-2018 were the four warmest years on record globally. ${ }^{11}$ India too has witnessed an increasing trend of heat wave over past several years and eleven out of fifteen warmest years were during the recent past fifteen years (2005-2019). ${ }^{12}$ Heat wave is a period of abnormal high temperatures, that occurs during the pre-monsoon (April-June) summer season. As India have different climatic zones, an arbitrary limit of maximum temperature of a station is considered as heat wave condition i.e., at least $40^{\circ} \mathrm{C}$ or more for plains, $37^{\circ} \mathrm{C}$ or more for coastal areas and at least $30^{\circ} \mathrm{C}$ or more for hilly regions. To declare a heat wave condition, India Meteorological Department (IMD) uses following criteria: (a) based on departure from normal- if departure from normal is $4.5^{\circ} \mathrm{C}$ to $6.4^{\circ} \mathrm{C}$ it is a heat wave and if it is $>6.4^{\circ} \mathrm{C}$ it is a severe heat wave (b) based on actual maximum temperature (for plain only)- when actual maximum temperature is $\geq 45^{\circ} \mathrm{C}$ it is a heat wave and when actual maximum temperature is $\geq 47^{\circ} \mathrm{C}$ it is a severe heat wave. To declare a heat wave, the above criteria should be met for at least at two station in a Meteorological sub-division for at least two consecutive days. A heat wave will be declared on the second day. ${ }^{13}$

\section{Effect of Heat Wave on Human Health}

In India, heat wave caused 24,223 deaths from 1992 to 2015 across various States. ${ }^{10}$ From year 2015 to 2018 the number of deaths reported by Integrated Disease Surveillance Programme (IDSP) were 2040, 1111, 384 and 25 respectively. In year 2019, the maximum number of deaths were from Bihar, Telangana and Andhra Pradesh.

The effects of exposure to heat can be directly heat related (heat related illnesses) or can contribute to a worsening 
of respiratory and cardiovascular diseases, electrolyte disorders and kidney problems. Heat related illnesses occur on a continuum from mild symptoms to fatalities. ${ }^{10}$ Different type of heat related illness includes: (i) Minor heat related Illnesses: Heat rash, heat edema, heat tetany, heat cramps, and heat syncope (ii) Major heat related IIInesses: Exertion associated collapse, heat exhaustion and heat stroke. The vulnerable population are people aged 65 and older, infants and young children, pregnant women, people with chronic medical conditions like diabetes mellitus, cardiovascular disease, mental disorders, neurological diseases, people on medications, outdoor workers, destitute and low-income population, people who exert in hot environment etc. ${ }^{14}$

\section{Agencies Managing Heat Wave and its Effects}

IMD, Ministry of Earth Sciences, is the nodal agency for providing current and forecast weather information, including warnings for all weather-related hazards. In year 2017, IMD introduced a system of exclusively heat related warnings, these warnings are valid for the next four days and are issued around 1600 hours IST daily during heat wave season. ${ }^{13}$

National Disaster Management Authority (NDMA) is the nodal agency that works on heat risk reduction and have prepared National guidelines for preparation of action plan-prevention and management of heat wave. The guideline aims to facilitate the stakeholders to prepare/ revise/update their Heat Action Plans by providing insights into various aspects related to heat risk reduction. The guideline also provided the roles and responsibilities for different stakeholders/ministries/departments that will help in their mobilization and coordination among them. ${ }^{13}$

MoHFW is the nodal agency that looks after health aspect of heat wave and has prepared guidelines on prevention and management of heat related illnesses. The guideline provide insight into various heat related illnesses, their management and prevention. The public health actions required for managing heat related illnesses are surveillance of heat related illnesses morbidity and mortality, investigation of heat related health event, pre-hospital and hospital care, logistics, training of doctors and nurses, awareness among public, coordination with multiple stakeholders, heat action plan for specific cities/ rural districts, particular care for vulnerable population groups and roping in Non-Government Organizations (NGOs) for spreading awareness on heat related illnesses. ${ }^{14}$ Since 2015, IDSP under MoHFW is collecting and compiling the data of heat related illnesses from seventeen States i.e., Andhra Pradesh, Bihar, Chhattisgarh, Delhi, Gujarat, Haryana, Jharkhand, Karnataka, Maharashtra, Madhya Pradesh, Odisha, Punjab, Rajasthan, Tamil Nadu, Telangana, Uttar Pradesh and West Bengal. In year 2019, the list of vulnerable States was increased to 23 States, the newly added States were Kerala,
Goa, Uttarakhand, Jammu \& Kashmir, Arunachal Pradesh and Himachal Pradesh. Currently information on morbidity and mortality of heat related illnesses is being captured on daily basis from health facility level, this information is being compiled at all district and from there to the States and then further at National level.

\section{Key Strategies in Coming year in Heat and Human} Health Activities

- Strengthening the Heat and Human Health Surveillance System: as per the suggestions and feedback received from various stakeholders at States, institutes and experts working on heat related illnesses the formats are being revised for making it more useful.

- Standardizing the Investigation of Deaths due to Suspected Heat Stroke Cases: at State/ district level the suspect heat related death is being investigated by a team of tehsildar/revenue officer, police officer and medical officer. A standardized format is being develop to make standardized system of heat death investigation.

- Developing State/ District/ City Specific Heat and Health Action Plan: States/districts/cities have potential geographic, climatic or other features specific to their region, therefore there is a need to develop region specific heat and health action plan in which they can describe the heat vulnerable areas, vulnerable populations, health infrastructures and other resources. It will help in prioritising location, communities and individuals. Action plan will enlist the resources, activities and identify the stakeholders with their defined roles and responsibilities with operational flowchart or table. The action plan will help in preparedness before season, response coordination during season and evaluation after season. This health sector specific heat action plan will be incorporated in State/ district/ city level heat action plan developed by revenue/ disaster management plan.

- Increasing Public Awareness and Community Outreach for disseminating messages on how to prevent extreme heat events. Efforts include the use of social media such as SMS, radio, WhatsApp, email, social media, caller tunes etc. Special efforts to reach vulnerable populations through inter-personal communications as well as other outreach methods.

- Developing Measures for Early Warning System/Alerts and Response at State, district and below district level. As IMD shares a daily five-day forecast at its website, a formal communication channel is being strengthened to alert health agencies for early response.

- Capacity Building with the help of training module among all level health care professionals to recognize and respond to heat related illnesses. 


\section{Green and Climate Resilient Healthcare Facilities}

Health care facilities are highly intensive resource consuming areas contributing significantly to carbon footprint globally. Globally, health sector contributes about 3-10\% of the National carbon footprint in the world..$^{15}$ In India, health sector roughly corresponds to about $5 \%$ of the National carbon footprint. ${ }^{16}$ At the same time, the already burdened health care facilities in the country are facing added challenges to the increasing health impacts due to climate change. In the last few decades, there have been reports of changes in frequency and intensity of climate and weather related events hugely affecting functioning of healthcare facilities and even collapsing during the most critical juncture. ${ }^{17,18}$ These have not only greatly affected the lives and health of the patients in the affected healthcare facilities but also, the healthcare professionals themselves whose services are critically required for the affected facilities and the communities too. ${ }^{18}$

A well-prepared and responsive healthcare facility is crucial for preventing and minimizing the health risks posed due to climate change. A green health care facility will help to optimally minimize the carbon footprint from the healthcare facilities. ${ }^{19,20}$ At the same time, climate resilient health facilities will help to deal the adverse health impacts due to extreme weather events like cyclones, floods, heat etc and will continue to give some critical services despite the extreme events impacting the health care facilities. The core principles to develop the healthcare facilities include health system models of care based on appropriate technology, building design and construction based on low carbon approaches, investment programs in renewable energy and energy efficiency, waste minimization and sustainable health system waste management, sustainable transport and water consumption policies etc. ${ }^{21}$

NCDC under MoHFW is incorporating both the green and climate resilient healthcare principles in revising Indian Public Health Service (IPHS) guidelines which deal on SubCentre, PHCs, CHCs, SDHs and District Hospitals and is considering to work in near future to other healthcare facilities.

\section{Conclusion}

The NPCCHH is a unique programme, with a futuristic vision to create a climate resilient healthcare system across the country. The key objectives include creation of awareness regarding CSDs among the general public, healthcare providers, policy makers etc, to strengthen the healthcare capacity to deal with CSDs, focus on health preparedness, develop inter and intra governmental, non-governmental partnerships, and to strengthen the research capacity in the country on CSDs. Incorporating the concept of climate change and human health in the already existing programmes will help raise the health standards of population through direct or indirect impacts. To enhance the expertise amongst the health professionals apart from efforts towards training of health professionals the concept of climate change and human health is being integrated in the medical and allied sciences curriculum through respective councils.

The NPCCHH is a platform which encourages inputs, opinions and suggestion from various stakeholders involved in climate change and human health related activities.

The programme acknowledges the contribution of various government and non-governmental bodies involved and looks forward for a constructive association with them.

\section{Conflicts of Interest: None}

\section{References}

1. United Nations. United Nations Framework Convention on Climate Change 1992. Available online: https:// unfccc.int/files/essential_background/background_ publications_htmlpdf/application/pdf/conveng.pdf. Accessed on 30 March 2020.

2. Edenhofer O, Pichs-Madruga O, Sokona Y et al. IPCC, 2014: Summary for policymakers. In: Climate change 2014: Mitigation of climate change. Contribution of working group III to the fifth assessment report of Intergovernmental Panel on climate change. Cambridge University Press, Cambridge, United Kingdom and New York, NY, USA. Available from: https://www.ipcc.ch/site/ assets/uploads/2018/02/ipcc_wg3_ar5_summary-forpolicymakers.pdf. Accessed on 30 March 2020.

3. Masson-Delmotte V, Zhai P, Pörtner $\mathrm{HO}$ et al. Intergovernmental Panel on Climate Change (IPCC). Summary for Policymakers. In Global Warming of 1.5 C; An IPCC Special Report on the impacts of global warming of $1.5 \mathrm{C}$ above pre-industrial levels and related global greenhouse gas emission pathways, in the context of strengthening the global response to the threat of climate change, sustainable development, and efforts to eradicate poverty. World Meteorological Organization: Geneva, Switzerland 2018;32. Available from: https://www.ipcc.ch/sr15/chapter/summary-forpolicy-makers/. Accessed on 12 March 2019.

4. Woodward KRA, Campbell-Lendrum D, Chadee DD, et al. Human health: impacts, adaptation, and co-benefits. In: Climate Change 2014: Impacts, Adaptation, and Vulnerability. Part A: Global and Sectoral Aspects. Contribution of Working Group II to the Fifth Assessment Report of the Intergovernmental Panel on Climate Change. Cambridge University Press, Cambridge, United Kingdom and New York, NY, USA 2014, pp.709-754. Available from: https://www.ipcc.ch/ site/assets/uploads/2018/02/WGIIAR5-Chap11_FINAL. 
pdf. Accessed on 30 March 2020.

5. Pandve HT. India's national action plan on climate change. Indian J Occup Environ Med 2009; 13(1): 17-9. Available from: https://www.ncbi.nlm.nih.gov/pmc/ articles/PMC2822162/. Accessed on 30 March 2020.

6. Ministry of Health \& Family Welfare, Government of India. National action plan for climate change \& human health. Available online: https://ncdc.gov.in/ WriteReadData/l892s/27505481411548674558.pdf. Accessed on 29 January 2020.

7. IQAir Air Visual. 2019 World air quality report. Available from: https://www.iqair.com/world-most-pollutedcities/world-air-quality-report-2019-en.pdf. Accessed on 30 March 2020.

8. Ministry of Environment, Forest and Climate Change. Government launches National Clean Air Programme (NCAP). Available from http://pib.nic.in/newsite/ mbErel. aspx? relid=175437. Accessed on 10 February 2020.

9. WHO. Ambient (Outdoor) Air Quality and Health. Available from: https://www.who.int/news-room/ fact-sheets/detail/ambient-(outdoor)-air-quality-andhealth. Accessed on 30 March 2020.

10. India State-Level Disease Burden Initiative Air Pollution Collaborators. The impact of air pollution on deaths, disease burden and life expectancy across the states of India: the global burden of disease study 2017. Lancet Planet Health 2019; 3: e26-39. Available from: https:// www.thelancet.com/journals/lanplh/article/PIIS25425196(18)30261-4/fulltext. Accessed on 30 March 2020.

11. World Meteorological Organization. WMO statement on the State of the global climate in 2018. Available online: https://library.wmo.int/doc_num.php?explnum_ id=5789. Accessed on 10 February 2020.

12. India Meteorological Department. Statement on climate of India during 2019. Available from: https:// mausam.imd.gov.in/backend/assets/press_release_ pdf/Statement_on_Climate_of_India_during_2019. pdf. Accessed on 10 February 2020.

13. National Disaster Management Authority. National Guidelines for preparation of action plan - prevention and management of heat wave October 2019. Available from: https://ndma.gov.in/images/guidelines/heatwav eguidelines.pdf. Accessed on 10 Feb 2020.

14. MoHFW. Guidelines on prevention and management of heat related illnesses 2015. Available from: http:// health.bih.nic.in/Operational\%20guideline/EMR\%20 Mohfw\%20heat\%20illnesses\%20-2015.pdf. Accessed on 10 February 2020.

15. Malik A, Lenzen M, McAlister S et al. The carbon footprint of Australian health care. Lancet Planet Health 2018; 2: e27-35. Available from: https://www.thelancet. com/journals/lanplh/article/PIIS2542-51961730180-8/ fulltext. Accessed on 30 March 2020.

16. Pichler PP, Jaccard IS, Weisz $U$ et al. International comparison of health care carbon footprints. Environ Res Lett. 2019; 14: 064004. Available from https:// iopscience.iop.org/article/10.1088/1748-9326/ab19e1. Accessed on 15 April 2020.

17. Bell JE, Brown $\mathrm{CL}$, Conlon $\mathrm{K}$ et al. Changes in extreme events and the potential impacts on human health. $J$ Air Waste Manage 2018; 69: 265-87. Available from: https://www.tandfonline.com/doi/full/10.1080/1096 2247.2017.1401017. Accessed on 15 April 2020.

18. Curtis S, Fair A, Wistow J et al. Impact of extreme weather events and climate change for health and social care systems. Environ Health 2017; 16: 128. Available from: https://ehjournal.biomedcentral.com/ articles/10.1186/s12940-017-0324-3. Accessed on 15 April 2020.

19. Chias P, Abad T. Green hospitals, green healthcare. Int J of Energy Prod \& Mgmt 2017; 2: 196-205. Available from: https://www.witpress.com/elibrary/ eq-volumes/2/2/1860. Accessed on 15 April 2020.

20. Dhillon VS, Kaur D. Green hospital and climate change: their interrelationship and the way forward. J Clin Diagn Res. 2015; 9(12): LE01-5. Available from: https:// www.ncbi.nlm.nih.gov/pubmed/26814377. Accessed on 15 April 2020.

21. Balbus J, Berry P, Brettle $M$ et al. Enhancing the sustainability and climate resiliency of health care facilities: a comparison of initiatives and toolkits. Rev Panam Salud Publica. 2016; 40(3): 174-80. Available from: https://www.ncbi.nlm.nih.gov/ pubmed/27991975. Accessed on 15 April 2020. 